\title{
The potential impact of COVID-19 on thyroid gland volumes among COVID-19 survivors
}

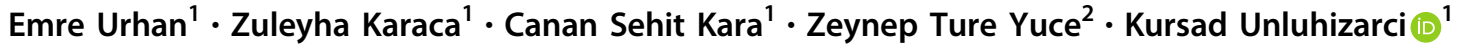

Received: 14 October 2021 / Accepted: 14 February 2022 / Published online: 3 March 2022

(c) The Author(s), under exclusive licence to Springer Science+Business Media, LLC, part of Springer Nature 2022

\begin{abstract}
Purpose Data about the effects of COVID-19 on the endocrine system are increasing over time. In the present study, we investigated the effects of COVID-19 on the thyroid gland among COVID-19 survivors by comparing them with healthy subjects.

Methods Adult COVID-19 survivors who were managed and followed up in the Infectious Disease clinic were asked to participate in this study. COVID-19 survivors were recruited via a convenience sampling and those who agreed to participate in this study were seen by endocrinologists for assessments. The blood tests were obtained for thyroid antibodies and thyroid function tests. Thyroid ultrasonography (USG) was done by the same physician. The ellipsoid formula was used for the calculation of thyroid gland volume.

Results 64 adult COVID-19 survivors and 70 control subjects were enrolled in the study. The COVID-19 survivors were evaluated at median 5.7 months (IQR: 4-6.5) (range: 2-7 months) after acute infection. The mean thyroid gland volume was significantly lower in COVID-19 survivors $(10.3 \pm 3.4 \mathrm{~mL})$ than in the controls $(14 \pm 5.3 \mathrm{~mL})(p=0.001)$. There was no significant difference in free triiodothyronine (fT3), free thyroxine (fT4) and thyroid-stimulating hormone (TSH) levels between the groups. Among the twelve patients who had thyroid function evaluated in acute COVID-19, fT3 values were lower in acute COVID-19 than at the time of USG evaluation $(3.04 \pm 0.41 \mathrm{vs} 3.47 \pm 0.31 \mathrm{pg} / \mathrm{mL}),(p=0.02)$. Among COVID-19 survivors, mild TSH elevation was detected in 4 (6.2\%) patients and all of the other COVID-19 survivors (93.7\%) were euthyroid.

Conclusions At 6 months after acute COVID, COVID-19 survivors had smaller thyroid gland volume than healthy controls, and only a few of the COVID-19 survivors had abnormal thyroid function.
\end{abstract}

Keywords COVID-19 $\cdot$ Thyroid gland volume $\cdot$ Thyroid function tests $\cdot$ SARS-CoV-2

\section{Introduction}

Coronavirus disease 2019 (COVID-19) is an infective disease caused by severe acute respiratory syndrome coronavirus-2 (SARS-CoV-2), which was first reported from China in November 2019. It has evolved into a pandemic and posed a significant global health risk [1-3]. It mainly affects the lungs, but its effects have also been

Kursad Unluhizarci

kursad@erciyes.edu.tr

1 Department of Endocrinology, Erciyes University Medical School, Kayseri, Turkey

2 Department of Infectious Diseases and Clinical Microbiology, Erciyes University Medical School, Kayseri, Turkey shown in many other systems, including the endocrine system [2-4]. The entry of SARS-CoV-2 into cells depends on angiotensin-converting enzyme 2 (ACE2) and transmembrane protease serine 2 (TMPRSS2) [5]. Data about the effects of COVID-19 on the endocrine system are accumulating over time. Abnormal thyroid function in the context of COVID-19 has been reported to be due to thyroiditis and Graves' disease $[2,6]$. TMPRSS2 and ACE2 expression in the thyroid gland were detected to be higher than in the lung according to cell culture examinations $[6,7]$. Therefore, the thyroid gland may be a target for COVID-19 [2, 7].

SARS-CoV-2 is structurally similar to SARS-CoV-1. Postmortem examinations of patients infected with SARSCoV-1 revealed virus associated cell damage in thyroid parafollicular and follicular cells [8]. SARS-CoV-2 may affect the thyroid gland indirectly by autoimmune changes, 
hyperimmune responses or directly by viral damage [9-11]. In addition, due to the detection of ACE2 and SARS-CoV-1 genome in the hypothalamic-pituitary system, it may lead to thyroid dysfunction with possible thyrotroph cell damage. Increasingly, cases of SARS-CoV-2-induced subacute thyroiditis and postpartum thyroiditis are being reported $[12,13]$. It has been reported in recent studies that COVID19 may cause thyroid dysfunction in both the acute and convalescence phases [1,2]. Although there are some recent but limited data, it is not well known the ultrasonographic alterations seen in COVID-19 survivors and whether any ultrasonographic alteration may predispose to develop future thyroid dysfunctions. In this study, we investigated the effects of COVID-19 on the thyroid gland among COVID-19 survivors by comparing them with healthy subjects.

\section{Patients and methods}

The present study was approved by the Ethics Committee of the Erciyes University Medical School. Between January 2021 and April 2021, adult COVID-19 survivors who were managed and followed up in the Infectious Disease clinic at around 3 months from acute COVID-19 were asked to participate in this study. Patients were recruited via a convenience sampling and those who agreed to participate in this study were seen by endocrinologists for assessments as detailed below. Exclusion criteria for the current study were a history of thyroid disease and surgery, neck radiation, pregnancy, use of medication that affects thyroid function, and pituitary/hypothalamic disease.

Healthy adults were recruited from the hospital staff in the same inclusion period as the COVID-19 survivors. Lack of history of COVID-19 diagnosis and COVID-19 symptoms within the six months were used for an inclusion criteria of healthy controls. Additionally, none of them have any acute or chronic disease and were not using any drug.

SARS-CoV-2 polymerase chain reaction of nasal and oral swab samples were used for the diagnosis of acute COVID-19 by using RNA, biospeedy nucleic acid extraction kit (Bioeksen R\&D Technologies, Istanbul, Turkey). The clinical characteristics of patients (status of oxygen demand, history of intensive care unit (ICU) hospitalization, intubation, and medications), prognostic markers of COVID-19 (lymphocyte count, C-reactive protein) and basic biochemical tests during the course of acute COVID19 were recorded. The patients were categorized as mild, moderate, and severe/critical disease severity according to the National Health Commission of China during acute COVID-19 [14] and the patients were classified according to their most severe phase. In mild disease, the symptoms were mild and there was no evidence of pneumonia on radiological examination. In moderate disease, respiratory system symptoms and fever were present and radiological examination revealed evidence of pneumonia. Severe/critical disease was characterized by the presence of any of the following symptoms; respiratory rate $\geq 30$ /minute, oxygen saturation $\leq 93 \%$, shock states, more than $50 \%$ progression of pneumonic infiltration within $24-48 \mathrm{~h}$ on radiological examination, and need for mechanical ventilation and ICU [14].

Blood tests were obtained between 0800 and 0900 for basal biochemical and hormonal investigations; anti-thyroid peroxidase (TPO), anti-thyroglobulin (Tg) antibodies, free triiodothyronine (fT3), free thyroxine (fT4) and thyroidstimulating hormone (TSH) from the participants. A subgroup of COVID-19 survivors who had thyroid function tests both in acute COVID-19 and convalescence were evaluated seperately.

Thyroid hormone levels and thyroid autoantibodies were measured by the electrochemiluminescence immunoassay (ECLIA) method (Cobas; Roche Diagnostics, Mannheim, Germany). Reference ranges were as follows: $\mathrm{TSH}=$ $0.27-4.20 \mu \mathrm{U} / \mathrm{mL}, \mathrm{fT} 4=0.93-1.97 \mathrm{ng} / \mathrm{dL}, \mathrm{fT} 3=2-4.4 \mathrm{pg} /$ $\mathrm{mL}$, anti-TPO $=0-34 \mathrm{U} / \mathrm{mL}$ and anti-Tg $=0-115 \mathrm{U} / \mathrm{mL}$. The titer values of antibodies higher than the upper reference range were considered positive.

Thyroid gland ultrasonography (USG) was performed on all participants by the same physician on the same day with blood tests, with a GE LOGIQ P5 ultrasound machine. Thyroid gland volume was calculated by ellipsoid formula: maximum length (L), width (W), and depth (D) for each lobe (volume $=\mathrm{L} \times \mathrm{D} \times \mathrm{W} \times 0.524)$. Total thyroid gland volume was calculated by summing the volumes of both lobes and if the maximum diameter of the isthmus was more than $5 \mathrm{~mm}$, it was also added $[15,16]$. In addition, participants with $\geq 1 \mathrm{~cm}$ nodules in the USG examination were excluded from the study.

\section{Statistical analysis}

The data was analyzed in the IBM SPSS program version 22. The Shapiro-Wilk test was used for data distribution. Data with normal distribution were shown as mean \pm standard deviation (SD) and non-normally distributed data were shown as median and interquartile range (IQR: 25-75\%). For the comparison of quantitative variables in two independent groups, the Mann-Whitney U test or two-sample independent $t$-test was performed according to the distribution of the data. For the comparison of categorical variables, Chi-square tests were performed. The COVID-19 disease severity groups were compared among themselves by one-way ANOVA and the Tukey HSD or GamesHowell test was performed according to data distribution for post-hoc analysis. The correlation analysis was performed 
by the Pearson or Spearman correlation analysis depending on the distribution of the data. The comparison of acuteCOVID-19 with post-COVID-19 data of the same patients was performed by using the Wilcoxon test or student's $t$ paired test. If the probability ( $p$ ) value was $<0.05$, it was considered statistically significant.

\section{Results}

Sixty-four adults with a history of COVID-19 and 70 healthy subjects were enrolled in the study. COVID-19 survivors were evaluated at a median of 5.7 months (IQR: 4-6.5) (range: 2-7 months) after the infection.There were no differences in age [38.8 \pm 11.2 years (range: $21-59$ ) and $36.3 \pm 10.4$ years (range: $22-59)$ ], body mass index (29.6 \pm 5.4 and $29.1 \pm 3.6 \mathrm{~kg} / \mathrm{m}^{2}$ ) , and gender $(50 \%$ male, $50 \%$ female and $45.7 \%$ male, $54.3 \%$ female) between COVID-19 survivors and controls, respectively.

Comorbidities of the COVID-19 survivors were also recorded (hypertension in six patients, diabetes mellitus in six patients, coronary artery disease in four patients). Among the patient group; 22 patients, 16 patients, and 26 patients were categorized as mild, moderate, and severe/ critical disease, respectively.

The mean thyroid gland volume was significantly lower in COVID-19 survivors $(10.3 \pm 3.4 \mathrm{~mL})$ than in the controls $(14 \pm 5.3 \mathrm{~mL})(p=0.001)$. Sex-specific analysis revealed that there were no difference in terms of thyroid gland volume in males $(11.09 \pm 3.09 \mathrm{~mL})$ and females $(9.57 \pm$ $3.58 \mathrm{~mL}$ ). There was no significant difference in TSH, fT4, fT3, anti-TPO and anti-Tg positivity between the two groups (Table 1). A normal and a smaller thyroid volume picture of USG was given in Fig. 1.

When the thyroid gland volume of COVID-19 survivors were compared according to their characteristics, such as lymphopenia (36 patients), history of oxygen demand (22 patients), hospitalisation in ICU (5 patients), intubation (2 patients), and steroid therapy (7 patients) during acute COVID-19 and gender and anti-TPO/Tg positivity, no significant difference was detected between subgroups (Table 2). We did not find any correlation between the highest serum C-reactive protein (CRP) levels determined during acute COVID-19 and the thyroid gland volume.

Among COVID-19 survivors, mild TSH elevation was detected in $4(6.2 \%)$ patients (patient 1: TSH $6.9 \mu \mathrm{U} / \mathrm{mL}$, fT4 $1.16 \mathrm{ng} / \mathrm{dL}$, fT3 $3.05 \mathrm{pg} / \mathrm{mL}$; patient 2: TSH $4.45 \mu \mathrm{U} /$ $\mathrm{mL}$, fT4 $1.18 \mathrm{ng} / \mathrm{dL}$, fT3 $3.30 \mathrm{pg} / \mathrm{mL}$; patient $3:$ TSH $4.88 \mu \mathrm{U} / \mathrm{mL}$, fT4 $1.20 \mathrm{ng} / \mathrm{dL}$, fT3 $3.02 \mathrm{pg} / \mathrm{mL}$; patient 4 : TSH $5.52 \mu \mathrm{U} / \mathrm{mL}$, fT4 $0.98 \mathrm{ng} / \mathrm{dL}$, fT3 $2.66 \mathrm{pg} / \mathrm{mL}$ ), and all of the other patients $(93.7 \%)$ were euthyroid. Among the four patients with abnormal thyroid function tests at the time of thyroid ultrasonography, three of these patients had
Table 1 Comparison of COVID-19 survivors and control subjects

\begin{tabular}{|c|c|c|c|}
\hline & $\begin{array}{l}\text { COVID-19 } \\
\text { survivors } \\
(N=64)\end{array}$ & $\begin{array}{l}\text { Control group } \\
(N=70)\end{array}$ & $\begin{array}{l}P \\
\text { value }\end{array}$ \\
\hline Gender & $\begin{array}{l}50 \% \text { male, } 50 \\
\% \text { female }\end{array}$ & $\begin{array}{l}45.7 \% \text { male, } \\
54.3 \% \text { female }\end{array}$ & 0.62 \\
\hline Age (years) & $\begin{array}{l}38.8 \pm 11.2 \\
\text { (range 21-59) }\end{array}$ & $\begin{array}{l}36.3 \pm 10.4 \text { (range } \\
22-59 \text { ) }\end{array}$ & 0.14 \\
\hline BMI $\left(\mathrm{kg} / \mathrm{m}^{2}\right)$ & $29.6 \pm 5.4$ & $29.1 \pm 3.6$ & 0.79 \\
\hline $\begin{array}{l}\text { TSH } \\
0.27-4.20 \mu \mathrm{U} / \mathrm{mL}\end{array}$ & $1.84(1.35-2.55)$ & $1.76(1.17-2.18)$ & 0.22 \\
\hline $\begin{array}{l}\mathrm{fT} 4 \\
0.93-1.97 \mathrm{ng} / \mathrm{dL}\end{array}$ & $1.19(1.07-1.27)$ & $1.20(1.05-1.32)$ & 0.82 \\
\hline $\begin{array}{l}\text { fT3 } \\
2-4.4 \mathrm{pg} / \mathrm{mL}\end{array}$ & $3.36 \pm 0.40$ & $3.26 \pm 0.40$ & 0.13 \\
\hline $\begin{array}{l}\text { Thyroid gland } \\
\text { volume }(\mathrm{mL})\end{array}$ & $10.3 \pm 3.4$ & $14 \pm 5.3$ & 0.001 \\
\hline $\begin{array}{l}\text { Anti-TPO positivity } \\
\text { Range: } 0-34 \mathrm{U} / \mathrm{mL}\end{array}$ & $5(7.8 \%)$ & $7(10 \%)$ & 0.65 \\
\hline $\begin{array}{l}\text { Anti-Tg positivity } \\
\text { Range: } 0-115 \mathrm{U} / \\
\mathrm{mL}\end{array}$ & $4(6.2 \%)$ & $5(7.1 \%)$ & 0.55 \\
\hline $\begin{array}{l}\text { Both antibody } \\
\text { positives }\end{array}$ & $2(3.1 \%)$ & $4(5.7 \%)$ & 0.68 \\
\hline
\end{tabular}

BMI body mass index, TSH thyroid-stimulating hormone, fT4 free thyroxine, $f T 3$ free triiodothyronine, $T P O$ thyroid peroxidase, $T g$ thyroglobulin

severe and one of them had moderate COVID-19 severity. All had negative anti-thyroid antibodies. Only one of the above mentioned patients (patient number 3 ) had thyroid function tests (TSH $3.63 \mu \mathrm{U} / \mathrm{mL}$, fT4 $1.25 \mathrm{ng} / \mathrm{dL}$, fT3 $3.08 \mathrm{pg} / \mathrm{mL}$ ) in acute COVID-19.

Only 12 COVID-19 survivors had their thyroid function checked during acute COVID-19 and no significant difference was found for TSH (median $1.46 \mu \mathrm{U} / \mathrm{mL}$ and $1.74 \mu \mathrm{U} /$ $\mathrm{mL}$, respectively) and fT4 levels (median $1.25 \mathrm{ng} / \mathrm{dL}$ and $1.17 \mathrm{ng} / \mathrm{dL}$, respectively) in comparison to post-COVID-19 period. Although within normal limits, the fT3 values in acute-COVID-19 $(3.04 \pm 0.41 \mathrm{pg} / \mathrm{mL})$ were significantly lower than their post-COVID-19 values $(3.47 \pm 0.31 \mathrm{pg} / \mathrm{mL})$ $(p=0.02)$. No significant difference in the thyroid gland volume was noted when patients were compared according to the severity of acute COVID-19.

\section{Discussion}

The present study revealed for the first time that thyroid gland volume was significantly lower in COVID-19 survivors than in healthy subjects with similar demographic characteristics. Additionally, mild TSH elevation was detected in 4 (6.2\%) COVID-19 survivors and the other COVID-19 survivors were euthyroid. 
Fig. 1 A Thyroid ultrasound image of a healthy subject with normal volume and normal internal echo. B Thyroid ultrasound image of a COVID19 survivor with smaller volume and hypoechogenic areas. * Lines represent the dimensions to calculate thyroid volumes (in addition to measurement of length from the most cranial to most caudal part of the lobe on a screen picture)

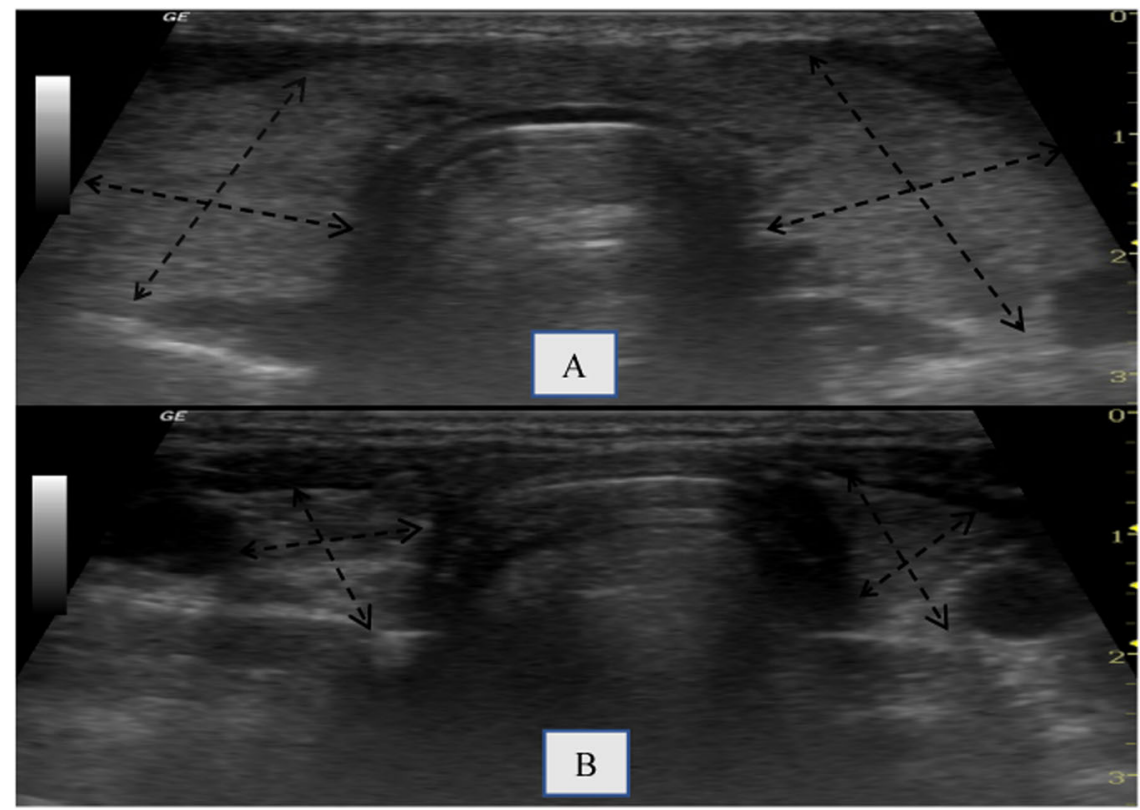

Table 2 Thyroid gland volumes according to some variables in COVID-19 survivors

\section{$P$ VALUE}

\begin{tabular}{llll}
\hline Gender & $\begin{array}{l}\text { Male } \\
(n=32)\end{array}$ & $\begin{array}{l}\text { Female } \\
(n=32)\end{array}$ & \\
& $\begin{array}{l}11.09 \pm 3.09 \\
(+)(\mathrm{N}=5)\end{array}$ & $\begin{array}{l}9.57 \pm 3.58 \\
(-)(\mathrm{N}=59)\end{array}$ & 0.07 \\
Anti-TPO & $\begin{array}{l}(31 \pm 4.94 \\
10.50 \pm 3.25\end{array}$ & 0.17 \\
Range: 0-34 U/mL & $(+)(\mathrm{N}=4)$ & $(-)(\mathrm{N}=60)$ & \\
Anti-Tg & $10.49 \pm 3.44$ & $7.87 \pm 1.48$ & 0.13 \\
Range: 0-115 U/mL & $(+)(\mathrm{N}=36)$ & $(-)(\mathrm{N}=28)$ & \\
Lymphopenia & $9.94 \pm 3.25$ & $10.83 \pm 3.60$ & 0.30 \\
& $(+)(\mathrm{N}=5)$ & $(-)(\mathrm{N}=59)$ & \\
ICU history & $10.48 \pm 4.11$ & $10.32 \pm 3.38$ & 0.91 \\
& $(+)(\mathrm{N}=2)$ & $(-)(\mathrm{N}=62)$ & \\
Intubation history & $13.66 \pm 0.56$ & $10.22 \pm 3.41$ & 0.16 \\
& $(+)(\mathrm{N}=22)$ & $(-)(\mathrm{N}=42)$ & \\
Oxygen demand & $10.27 \pm 3.58$ & $10.36 \pm 3.30$ & 0.91 \\
& $(+)(\mathrm{N}=7)$ & $(-)(\mathrm{N}=57)$ & \\
Steroid therapy history & $10.45 \pm 3.50$ & $10.31 \pm 3.42$ & 0.92 \\
\hline
\end{tabular}

$I C U$ intensive care unit, $T P O$ thyroid peroxidase, $T g$ thyroglobulin

It has been confirmed that COVID-19 is not only a localized infection of the lungs but it also leads to multisystemic disorders. Data are accumulating regarding this issue, including the thyroid gland. Although it is well known that acute and reversible changes of the thyroid gland functions may be observed in other infectious diseases, the long-term temporary or reversible results of COVID-19 arouse more curiosity. Since our patients were evaluated at a median of 5.7 months after acute COVID-19, our results may suggest the longer-term effect of acute COVID-19.

In a study by Lui et al. [17], 79 patients were evaluated for a median of 2 months after the diagnosis of COVID- 19 . The authors found that thyroid gland volume was lower than in control subjects, although the difference did not reach statistical significance. The authors realized that thyroid gland volume was significantly lower in patients with a higher SARS-CoV-2 viral load, specifically among men. The mechanisms regarding the effect of COVID-19 on the thyroid gland are not yet fully clear. As we found in our study, the authors did not find any association with systemic inflammation markers such as CRP and the thyroid gland volume [17]. We did not detect any relationship between the inflammatory markers, gender, and severity of disease with thyroid gland volume.

Pizzocaro et al. recruited 58 patients with COVID-19 associated thyrotoxicosis where $23(39.7 \%)$ of the patients died. Among the rest of the patients, 29 patients were enrolled to the prospective study [18]. The authors reported that all but one subject with COVID-19 related thyrotoxicosis became euthyroid after a median of 90 days while one-third of the patients revealed hypoechogenicity on ultrasound evaluation associated with higher TSH values at follow-up. They concluded that this ultrasonographic alteration may predispose to develop late-onset thyroid dysfunction [18]. However, although the authors give thyroid gland volume for each patient, there is no comment on thyroid gland volumes in comparison to any control group or any comparison between the recruitment period and at the end of follow-up.

In accordance to the exhibition of SARS-CoV-2 nucleocapsid antigen in the epithelial cells lining thyroid 
follicles, the potential direct viral atrophic effect on the thyroid, rather than systemic inflammation or non-thyroidal illness syndrome should be considered in the pathogenesis of COVID-19 associated thyroid gland disorders [17]. SARS-CoV-2 may disrupt the thyroid microstructure in the acute period and may initiate thyrocyte damage. This injury may result in a decrease in thyroid gland volume over a longer period, even if thyroid hormone levels have no abnormality. In addition to cases of COVID-19-induced subacute thyroiditis presenting with classical signs and symptoms, cases of painless thyroiditis have also been reported [13, 19]. Subacute thyroiditis may be associated with smaller thyroid gland volume in the recovery phase [20]. In the present study, subacute thyroiditis was not detected in our patients, noting that many patients were treated with glucocorticoids during acute COVID-19.

SARS-CoV-2 and SARS-CoV-1 have been shown in thyroid cells obtained by autopsy samples [21, 22]. In addition, autopsy examinations of SARS-CoV-1-infected patients showed a decrease in staining and intensity of pituitary TSH-secreting cells compared to healthy controls [23]. We may speculate that SARS-CoV-2 and SARS-CoV1 may trigger possible damage with its affinity to thyroid and pituitary cells. Interestingly, the ACE2 receptor, which is required for cell invasion of SARS-CoV-2, was detected more intensively in the thyroid gland than in the lung which may lead to the thyroid gland as a viral target [24].

In a previous study, 61 SARS-CoV-1 survivors, with no known thyroid disease were evaluated 3 months after postrecovery and hypothyroidism was detected in 4 (6.6\%) patients [25]. It is now well known that COVID-19 may trigger immune system activation and autoimmune changes $[24,26]$. The cytokine storm and hyperimmune response during COVID-19 may lead to destructive and inflammatory thyroiditis [10].

The role and/or existence of thyroid autoimmunity in COVID-19 survivors has been investigated. Although we did not detect any difference with healthy subjects for antibody positivity, our study was cross-sectional and was not able to evaluate the longitudinal changes in anti-thyroid antibodies. On the other hand, Lui et al. compared the anti$\mathrm{Tg}$ and anti-TPO titers of 104 COVID-19 patients during the acute infection period and in 3 months after postCOVID-19 and they revealed a significant increase in antibody titers [27]. In an another study, Lui et al. [28] evaluated the prevalence and predictors of long COVID-19 and the potential role of thyroid function and autoimmunity in 204 patients. They revealed that apart being female, higher SARS-CoV-2 viral load increase tendency to long COVID-19. However, the authors demonstrated that most of the thyroid dysfunction recovers spontaneously and patients with positive anti-TPO have more likely symptom resolution. Similarly, Clarke et al. also showed the preservation of thyroid and adrenal gland functions three months after COVID-19 [29].

Khoo et al. evaluated 334 patients with acute COVID-19 diagnosis and revealed that euthyroidism was present in $85.2 \%$ of patients. Among these 334 patients, 55 were followed for a median of 2.5 months, and 47 patients were still euthyroid, mildly increased TSH values were found in 2 patients, mildly low fT4 values were found in 4 patients, and mildly decreased TSH values were found in 2 patients [30]. Chen et al. showed TSH values lower than the normal range in $28(56 \%)$ of 50 COVID-19 patients in the acute period and found significantly lower TSH and total T3 values compared to healthy subjects and explained this situation as sick euthyroid syndrome. When patients with abnormal thyroid function tests were re-evaluated after the recovery period, no difference was detected compared to healthy subjects [1]. Lui et al. showed abnormal thyroid function tests in only $25(13.1 \%)$ patients of 191 COVID19. When 10 patients were followed for a median of one month, thyroid hormone normalization was detected in 6 patients and abnormality persisted in 4 patients [11].

In our study, thyroid hormone levels were evaluated in 12 patients during the acute period and all were euthyroid. Only $4(6.2 \%)$ of 64 patients had mild elevations in TSH values and there was no difference for thyroid hormone levels compared to healthy subjects in the post-COVID-19 period. Recovery of thyroid hormone abnormalities in the acute period does not mean that possible sequelae of COVID-19 in the thyroid gland will be completely normalized. Mildly elevated TSH values may be the recovery from non-thyroidal illness syndrome in acute COVID-19, however, those elevated TSH values may also be a precursor of overt hypothyroidism in the later periods and hypothyroidism may be the result of decreased thyroid gland volume. The visible picture of our study may be an early stage of a subclinical injury with the decrease in the thyroid gland volume. A longer follow-up may be needed to clarify this picture fully.

There are some limitations of this study such as its crosssectional design, which did not reveal the causalitiy and lack of control of non-COVID-19 infection survivors. The severity classification of COVID-19 used in the present study was based mostly on clinical findings and it does not include viral load. Although we could not evaluate viral load, which may be a limitation of the study, the viral load may not always correlate with disease severity. The thyroid function in acute COVID-19 was only available in a minority of the COVID-19 survivors and thyroid parenchymal changes have not been specifically evaluated. In addition to being a cross-sectional study, this study has also retrospective nature, thus anti-thyroid antibodies were not available at COVID-19. Additionally, if the patients give informed consent they were recruited via a convenience 
sampling and we cannot exclude a selection bias done by Infection Disease Department where the patients were directed to Endocrinology Department.

In conclusion, COVID-19 survivors had smaller thyroid gland volume and only a minority of them had abnormal thyroid function. Further prospective studies are needed for more precise mechanisms and data.

\section{Data availability}

The datasets generated and/or analysed during the current study are available from the corresponding author on reasonable request.

\section{Compliance with ethical standards}

Conflict of interest The authors declare no competing interests.

Publisher's note Springer Nature remains neutral with regard to jurisdictional claims in published maps and institutional affiliations.

\section{References}

1. M. Chen, W. Zhou, W. Xu, Thyroid function analysis in 50 patients with COVID-19. Thyroid 31(1), 8-11 (2021). https://doi. org/10.1089/thy.2020.0363

2. W. Wang, X. Su, Y. Ding, W. Fan, W. Zhou, J. Su, Z. Chen, H. Zhao, K. Xu, K. Qin et al. Thyroid function abnormalities in COVID-19 patients. Front Endocrinol. (Lausanne) 19(11), 623792 (2021). https://doi.org/10.3389/fendo.2020.623792

3. C. Huang, Y. Wang, X. Li, L. Ren, J. Zhao, J. Hu, L. Zhang, G. Fan, J. Xu, X. Gu et al. Clinical features of patients infected with 2019 novel coronavirus in Wuhan, China. Lancet 395(10223), 497-506 (2020). https://doi.org/10.1016/S0140-6736(20)30183-5

4. N. Chen, M. Zhou, X. Dong, J. Qu, F. Gong, Y. Han, Y. Qiu, J. Wang, Y. Liu, Y. Wei, et al. Epidemiological and clinical characteristics of 99 cases of 2019 novel coronavirus pneumonia in Wuhan, China. Lancet 395(10223), 507-513 (2020). https://doi. org/10.1016/S0140-6736(20)30211-7

5. E. Lazartigues, M.M. Qadir, F. Mauvais-Jarvis, Endocrine Significance of SARS-CoV-2's Reliance on ACE2. Endocrinology 161(9), bqaa108 (2020). https://doi.org/10.1210/endocr/bqaa108

6. S.A. Clarke, A. Abbara, W.S. Dhillo. Impact of COVID-19 on the Endocrine System-a mini-review. Endocrinology (2021). https:// doi.org/10.1210/endocr/bqab203

7. M. Rotondi, F. Coperchini, G. Ricci, M. Denegri, L. Croce, S.T. Ngnitejeu, L. Villani, F. Magri, F. Latrofa, L. Chiovato, Detection of SARS-COV-2 receptor ACE-2 mRNA in thyroid cells: a clue for COVID-19-related subacute thyroiditis. J Endocrinol Invest 44(5), 1085-1090 (2021). https://doi.org/10.1007/s40618-020-01436-w

8. L. Wei, S. Sun, C.H. Xu, J. Zhang, Y. Xu, H. Zhu, S.C. Peh, C. Korteweg, M.A. McNutt, J. Gu, Pathology of the thyroid insevere acute respiratory syndrome. Hum. Pathol. 38(1), 95-102 (2007). https://doi.org/10.1016/j.humpath.2006.06.011

9. A. Lania, M.T. Sandri, M. Cellini, M. Mirani, E. Lavezzi, G. Mazziotti, Thyrotoxicosis in patients with COVID-19: the THYRCOV study. Eur. J. Endocrinol. 183(4), 381-387 (2020). https://doi.org/10.1530/EJE-20-0335

10. P. Caron, Thyroiditis and SARS-CoV-2 pandemic. Endocrine 72 (2), 326-331 (2020). https://doi.org/10.1007/s12020-021-02689-y
11. D.T.W. Lui, C.H. Lee, W.S. Chow, A.C.H. Lee, A.R. Tam, C.H.Y. Fong, C.Y. Law, E.K.H. Leung, K.K. Wang, K.C.B. Tan, et al. Thyroid dysfunction in relation to immune profile, disease status, and outcome in 191 patients with COVID-19. J. Clin. Endocrinol. Metab. 106(2), 926-935 (2021). https://doi.org/10.1210/clinem/dgaa813

12. S. Mizuno, H. Inaba, K.I. Kobayashi, K. Kubo, S. Ito, T. Hirobata, G. Inoue, T. Akamizu, N. Komiya., A case of postpartum thyroiditis following SARS-CoV-2 infection. Endocr. J. 68(3), 371-374 (2021). https://doi.org/10.1507/endocrj.EJ20-0553

13. A. Brancatella, D. Ricci, D. Cappellani, N. Viola, D. Sgrò, F. Santini, F. Latrofa, Is subacute thyroiditis an underestimated manifestation of SARS-CoV-2 infection? insights from a case series. J Clin Endocrinol Metab 105(10), dgaa537 (2020). https:// doi.org/10.1210/clinem/dgaa537

14. "COVID-19 Diagnosis and Treatment Guideline in China (7th ed.). National Health Commission of the People's Republic of China. (http://www.nhc.gov.cn/)

15. W. Shabana, E. Peeters, M.D. Maeseneer, Measuring thyroid gland volume: should we change the correction factor? AJR Am. J. Roentgenol. 186(1), 234-236 (2006). https://doi.org/10.2214/ AJR.04.0816

16. M. Dighe, R. Barr, J. Bojunga, V. Cantisani, M.C. Chammas, D. Cosgrove, X.W. Cui, Y. Dong, F. Fenner, M. Radzina, et al. Thyroid ultrasound: state of the art part 1- thyroid ultrasound reporting and diffuse thyroid diseases. Med Ultrason 19(1), 79-93 (2007). https://doi.org/10.11152/mu-980

17. D.T.W. Lui, M.M.H. Fung, K.W.H. Chiu, C.H. Lee, W.S. Chow, A.C.H. Lee, A.R. Tam, P. Pang, T.Y. Ho, C.H.Y. Fong et al. Higher SARS-CoV-2 viral loads correlated with smaller thyroid volumes on ultrasound among male COVID-19 survivors. Endocrine 74(2), 205-214 (2021). https://doi.org/10.1007/s12020-021$02855-2$

18. A. Pizzocaro, P. Colombo, W. Vena, S. Ariano, P. Magnoni, F. Reggiani, G. Favacchio, M. Mirani, E. Lavezzi, A. Voza et al. Outcome of SARS-CoV-2-related thyrotoxicosis in survivors of COVID-19: a prospective study. Endocrine 73(2), 255-260 (2021). https://doi.org/10.1007/s12020-021-02758-2

19. M. Stasiak, A. Lewinski, New aspects in the pathogenesis and management of subacute thyroiditis. Rev. Endocr. Metab. Disord. 22 (4), 1027-1039 (2021). https://doi.org/10.1007/s11154-021-09648-y

20. N. Zhao, S. Wang, X.J. Cui, M.S. Huang, S.W. Wang, Y.G. Li, L. Zhao, W.N. Wan, Y.S. Li, Z.Y. Shan et al. Two-years prospective follow-up study of subacute thyroiditis. Front Endocrinol. (Lausanne) 11, 47 (2000). https://doi.org/10.3389/fendo.2020.00047

21. A.M. Poma, D. Bonuccelli, R. Giannini, E. Macerola, P. Vignali, C. Ugolini, L. Torregrossa, A. Proietti, M. Pistello, A. Basolo et al. COVID-19 autopsy cases: detection of virus in endocrine tissues. J. Endocrinol. Invest 30, 1-6 (2021). https://doi.org/10. 1007/s40618-021-01628-y

22. P. Caron, Thyroid disorders and SARS-CoV-2 infection: From pathophysiological mechanism to patient management. Ann Endocrinol (Paris) 81(5), 507-510 (2020). https://doi.org/10.1016/ j.ando.2020.09.001

23. L. Wei, S. Sun, J. Zhang, H. Zhu, Y. Xu, Q. Ma, M.A. McNutt, C. Korteweg, J. Gu, Endocrine cells of the adenohypophysis in severe acute respiratory syndrome (SARS). Biochem Cell Biol. 88 (4), 723-730 (2010). https://doi.org/10.1139/O10-022

24. M.Y. Li, L. Li, Y. Zhang, X.S. Wang, Expression of the SARSCoV-2 cell receptor gene ACE2 in a wide variety of human tissues. Infect. Dis. Poverty 9(1), 45 (2021). https://doi.org/10.1186/ s40249-020-00662-x

25. M.K.S. Leow, D.S.K. Kwek, A. Wei-Keong, K.C. Ong, G.J.L. Kaw, L.S.U. Lee, Hypocortisolism in survivors of severe acute respiratory syndrome (SARS). Clin. Endocrinol. (Oxf.) 63(2), 197-202 (2005). https://doi.org/10.1111/j.1365-2265.2005.02325.x 
26. R. Kerslake, M. Hall, H.S. Randeva, D.A. Spandidos, K. Chatha, I. Kyrou, E. Karteris, Co-expression of peripheral olfactory receptors with SARS-CoV-2 infection mediators: Potential implications beyond loss of smell as a COVID-19 symptom. Int J. Mol. Med 46 (3), 949-956 (2020). https://doi.org/10.3892/ijmm.2020.4646

27. D.T.W. Lui, C.H. Lee, W.S. Chow, A.C.H. Lee, A.R. Tam, C.H.Y. Fong, C.Y. Law, E.K.H. Leung, K.K. Wang, K.C.B. Tan, et al. Insights from a prospective follow-up of thyroid function and autoimmunity among COVID-19 survivors. Endocrinol Metab (Seoul.) 36(3), 582-589 (2021). https://doi.org/10.3803/EnM.2021.983

28. D.T.W. Lui, C.H. Lee, W.S. Chow, A.C.H. Lee, A.R. Tam, P. Pang, T.Y. Ho, C.H.Y. Fong, C.Y. Law, E.K.H. Leung et al. Long COVID in patients with mild to moderate disease: do thyroid function and autoimmunity play a role? Endocr. Pr. 27(9), 894-902 (2021). https://doi.org/10.1016/j.eprac.2021.06.016

29. S.A. Clarke, M. Phylactou, B. Patel, E.G. Mills, B. Muzi, C. Izzi-Engbeaya, S. Choudhury, B. Khoo, K. Meeran, A.N. Comninos et al. Normal adrenal and thyroid function in patients who survive COVID-19 infection. J. Clin. Endocrinol. Metab. 106(8), 2208-2220 (2021). https://doi.org/10.1210/clinem/dga b349

30. B. Khoo, T. Tan, S.A. Clarke, E.G. Mills, B. Patel, M. Modi, M. Phylactou, P.C. Eng, L. Thurston, E.C. Alexander, et al. Thyroid function before, during, and after COVID-19. J Clin Endocrinol Metab 106(2), 803-811 (2021). https://doi.org/10.1210/clinem/ dgaa 830 